\title{
Analysis of a Hybrid Mechanical Regenerative Braking System
}

\author{
Matthew Toh Xiang Wen ${ }^{1,}$ and Douglas Tong Kum Tien ${ }^{2,1}$ \\ ${ }^{1}$ School of Engineering, Taylor's University, Malaysia \\ ${ }^{2}$ School of Engineering, Taylor's University, Malaysia
}

\begin{abstract}
Regenerative braking systems for conventional vehicles are gaining attention as fossil fuels continue to be depleted. The major forms of regenerative braking systems include electrical and mechanical systems, with the former being more widely adopted at present. However mechanical systems are still feasible, including the possible hybrid systems of two mechanical energy recovery systems. A literature study was made to compare the various mechanical energy recovery systems. These systems were compared based on their advantages and disadvantages with regards to energy storage, usage, and maintenance. Based on the comparison, the most promising concept appeared to be one that combined the flywheel and the pneumatic energy recovery systems. A CAD model of this hybrid system was produced to better visualise the design. This was followed by analytical modelling of the energy recovery systems. The analysis indicated that the angular velocity had an extremely significant impact on the power loss and energy efficiency. The results showed that the hybrid system can provide better efficiency but only when operating within certain parameters. Future work is required to further improve the efficiency of this hybrid system.
\end{abstract}

\section{Introduction}

The slowing down or stopping of a moving automotive vehicle or machine is known as braking. Braking is commonly performed through mechanical means such as the use of friction brakes. Stationary brake pads are forced against the rotating brake discs mounted on the driveshaft to slow it down or to bring it to a stop. Kinetic energy from the rotating driveshaft is transformed into heat as a result of the friction between the brake pads and discs. This heat dissipation could cause energy losses of up to 30 percent [1] leading to an increase in fuel consumption. To minimize the loss, part of this energy could be captured and reused through a regenerative braking system (RBS).

Majority of road vehicles depend on fossil fuel to power an internal combustion engine (ICE). Efforts are being made to reduce fuel consumption. Research into RBS being one of these efforts. RBS are typically mechanical, electrical, or chemical systems that allow the stored energy to be reused to accelerate the vehicle. High-tech hybrid systems have been produced which combine the conventional brakes with a RBS. A RBS usually combines

${ }^{1}$ Corresponding author: DouglasKumTien.Tong@taylors.edu.my 
one method of energy storage with one method of energy conversion [2]. At present, the electrical storage hybrid vehicles appeal to the consumer market with the environmentfriendly concept and reduction in fuel costs for the end user [3].

A large amount of energy is usually lost during transformations of energy. Since energy is lost due to various factors such as friction, air resistance, and electrical resistance, the increase in the number of energy transformations will only cause a decrease in energy efficiency. A battery storage system shows this effect as it contains energy conversions of mechanical to electrical and to chemical to store the energy from braking. Besides the losses of energy, batteries are made up of rare-earth elements, increasing maintenance costs due to replacement of batteries after several years of use [4]. Furthermore the batteries are only operated in $55 \%$ to $65 \%$ of the total state of charge due to discharging efficiencies and to prolong battery life [5].

Currently, the public is becoming more aware about the kinetic energy recovery systems (KERS) that use batteries to store energy as these are being integrated into the latest models of everyday road vehicles. The electrical KERS however have limitations as they are less effective at lower speeds and require conventional brakes to provide sufficient braking. This is crucial when driving conditions vary, such as low-friction road surfaces or when driving in the rain.

Another form of energy recovery systems (ERS) also takes advantage of the inertia of the vehicle, converting kinetic energy of the moving wheels and driveshaft into stored mechanical energy and then releasing this energy back to the driveshaft for acceleration. Examples of these ERS include flywheel systems, pressurised accumulator systems, elastomeric systems, and regenerative shock absorber systems [4].

As the wheels of a vehicle are rotating, it follows that storage of energy in a rotational form would be able to reduce energy losses due to reducing the number of energy transformations. Flywheels can store energy in the form of rotational kinetic energy. Flywheels are popular mechanical energy recovery systems, as they have high power densities and are able to compete with batteries in power storage. Flywheel KERS have been used before and have shown up to $30 \%$ fuel reduction [4]. The flywheel KERS is simple in design with a clutch that connects the driveshaft to the flywheel during braking and thus helps with the braking of the vehicle while storing energy in the flywheel. A $65 \mathrm{~kg}$ flywheel KERS can store up to $60 \mathrm{~kW}$ of power and $580 \mathrm{~kJ}$ of energy for a $1800 \mathrm{~kg}$ vehicle [4].

Pressurised accumulators such as pneumatic or hydraulic systems use pressurised fluids to store energy. Gear pumps connect to the driveshaft that are driven to push air into the accumulators to be stored. A pneumatic accumulator can store high amounts of energy. Storage of up to $400 \mathrm{~kJ}$ or energy, with hydraulic accumulators storing about $90 \mathrm{~kJ}$ of energy have been shown [4]. Energy storage is however limited to the size of the accumulator and efficiencies of the accumulators at variable speeds. At low speeds, fixed mechanical losses cause drops in efficiency [6]. Elastomeric systems are able to store energy in the form of torsional energy if connected to the driveshaft and a fixed end, but store low energy. Storage of energy of about only $30 \mathrm{~kJ}$ is available, albeit for a long time [4]. The elastomer will however require frequent replacements due to decomposition caused by hysteresis. Regenerative shock absorbers recover energy from vertical oscillations of the vehicle, but only show at most a $10 \%$ improvement in efficiency [4]. Furthermore, smooth surfaces may not provide the maximum efficiency increase and may not be worth implementing due to the additional mass of the system.

Based on the review of literature, this study focused on the simulation of a mechanically-exclusive system that combines two mechanical KERS. The intention was to minimize the number of energy transformations and therefore maximize the amount of power delivered to the wheels which would reduce fuel consumption. 


\section{Research Methodology}

\subsection{Concept Comparisons}

Various theoretical designs of hybrid mechanical RBS were conceptualised based on a critical literature review of mechanical systems. The designs were then compared amongst each other to determine the most suitable concept for further analysis. A theoretical design of a non-hybrid mechanical RBS was also produced and analyzed for comparison against the hybrid concept.

\subsubsection{Advantages and Disadvantages of Energy Recovery Systems}

The previously mentioned ERS were compared with regards to their advantages and disadvantages concerning energy storage, energy losses, longevity of life and other relevant parameters. Table 2.1 summarises these advantages and disadvantages for each ERS.

Table 2.1. Advantages and disadvantages of various energy recovery systems

\begin{tabular}{|c|c|c|}
\hline $\begin{array}{l}\text { Energy Recovery } \\
\text { System }\end{array}$ & Advantages & Disadvantages \\
\hline Electric & $\begin{array}{l}\text { Proven technology } \\
\text { Readily available in the market }\end{array}$ & $\begin{array}{l}\text { Costly due to } \\
\text { replacements } \\
\text { Losses of energy due to } \\
\text { energy transformations } \\
\text { Long recharging times }\end{array}$ \\
\hline Flywheel & $\begin{array}{l}\text { Reduced losses during energy } \\
\text { capture } \\
\text { High energy storage capabilities } \\
\text { Technology well proven }\end{array}$ & $\begin{array}{l}\text { Loss of rotational energy } \\
\text { over time due to friction } \\
\text { and air resistance }\end{array}$ \\
\hline Hydraulic/Pneumatic & $\begin{array}{l}\text { Very low losses during energy } \\
\text { storage } \\
\text { Not as costly as other ERS }\end{array}$ & Limited energy storage \\
\hline Elastomeric & $\begin{array}{l}\text { Ejection characteristic for high } \\
\text { acceleration }\end{array}$ & $\begin{array}{c}\text { Low life span } \\
\text { Limited energy storage }\end{array}$ \\
\hline
\end{tabular}

Extensive research is currently conducted into hybrid electrical-mechanical RBS and it is as considered one of the more attractive fields of research for energy regeneration. However based on the literature reviewed on the ERS, a fully mechanical hybrid RBS can also be promising. Mechanical systems such as flywheels have the ability to capture and store high amounts of energy, while hydraulic or pneumatic systems are not costly and have low energy storage losses. The accumulator system is also able to charge and discharge more periodically than batteries that require lengthy recharging durations. By combining two of these mechanical ERS based on their advantages in energy storage, losses, or lifespan, it was anticipated that a more energy efficient systems could be produced. 


\subsubsection{Selection of Design Concept for Analysis}

These hybrid system design concepts include various combinations of the flywheel, hydraulic, and elastomeric ERS. As hybrid RBS consists of two main steps of energy harvesting and energy storage, the hybrid mechanical system will implement the same concept with two mechanical systems to collect and store energy from braking respectively.

As energy harvesting or capture systems require the ability to store a high initial amount of energy from the high angular velocity of the wheels of a vehicle, high storage capacity systems are preferred. Flywheel systems fit this category as they are able to store high amounts of energy while keeping the energy in the form of rotational energy, minimising the number of energy transformations and thus reducing the energy losses incurred. A hollow cylinder flywheel is also able to minimise the chance of disintegration at too high speeds [7].

Hydraulic, pneumatic and elastomeric systems are not as suitable for the initial energy capture and storage compared to the flywheel due to their limited energy storage. Hydraulic and pneumatic accumulators are limited to the amount of energy stored based on the size of the accumulators, while elastomerics under high usage conditions undergo hysteresis, requiring frequent replacements.

With flywheels identified as the most suitable system for initial energy capture and storage, a secondary energy storage system in the form of either the pressurised accumulator or elastomer can be considered for storing a portion of the initial energy. The accumulator has low energy losses which allows efficient energy storage, while the elastomer has an ejection characteristic that allows for acceleration during energy transfer back to the flywheel. As the flywheel will be storing energy as rotational energy, the transfer to the secondary energy storage in the form of rotation is preferred, once again to reduce losses. Both the accumulator and elastomer are able to utilise rotational motion, with accumulators running on gear pumps and elastomers storing energy through torsion. However, the decomposition of the elastomers in elastomeric systems is unavoidable. Thus, the pneumatic or hydraulic accumulators would be more effective in terms of lifespan and maintenance. As pneumatic accumulators use air or gas as opposed to liquids such as oil that is used by hydraulics, they are preferred for high speed applications due to the lower viscosity of gases. With potentially high speeds of the wheels and thus the flywheel, the pneumatic accumulator would be the more viable option.

A direct comparison was made between a non-hybrid mechanical system and the hybrid mechanical RBS was done by modeling them analytically. As the hybrid mechanical RBS selected for analysis was the flywheel-pneumatic system, the conventional mechanical RBS that was simulated for comparison was be the flywheel RBS. This comparison would show any changes in efficiency due to the addition of the pneumatic accumulator to the flywheel.

\subsection{Design of Regenerative Braking Systems}

The concept of combining two mechanical ERS to form a hybrid mechanical RBS is shown in Figure 2.1. The initial energy capture and storage system directly collects energy from the driveshaft connected during braking, and then transfers the energy captured to the secondary energy storage system. The stored energy is transferred back to the initial energy storage system and thus to the driveshaft during the acceleration of the vehicle. 


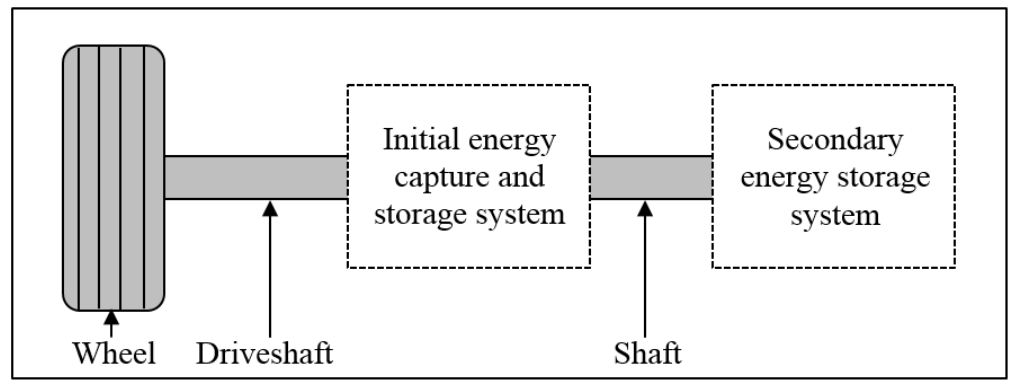

Fig. 2.1. General combination of systems for conceptualised hybrid mechanical RBS

\subsubsection{Flywheel Regenerative Braking System}

Flywheels by themselves are able to store large amounts of energy but lose energy over time due to air resistance and friction losses of the bearing. Figure 2.2 shows the flywheel that connects to the driveshaft through a conventional clutch system, such as those found in manual transmission vehicles. As the system is not a hybrid system, only one ERS is used to both capture and store energy.

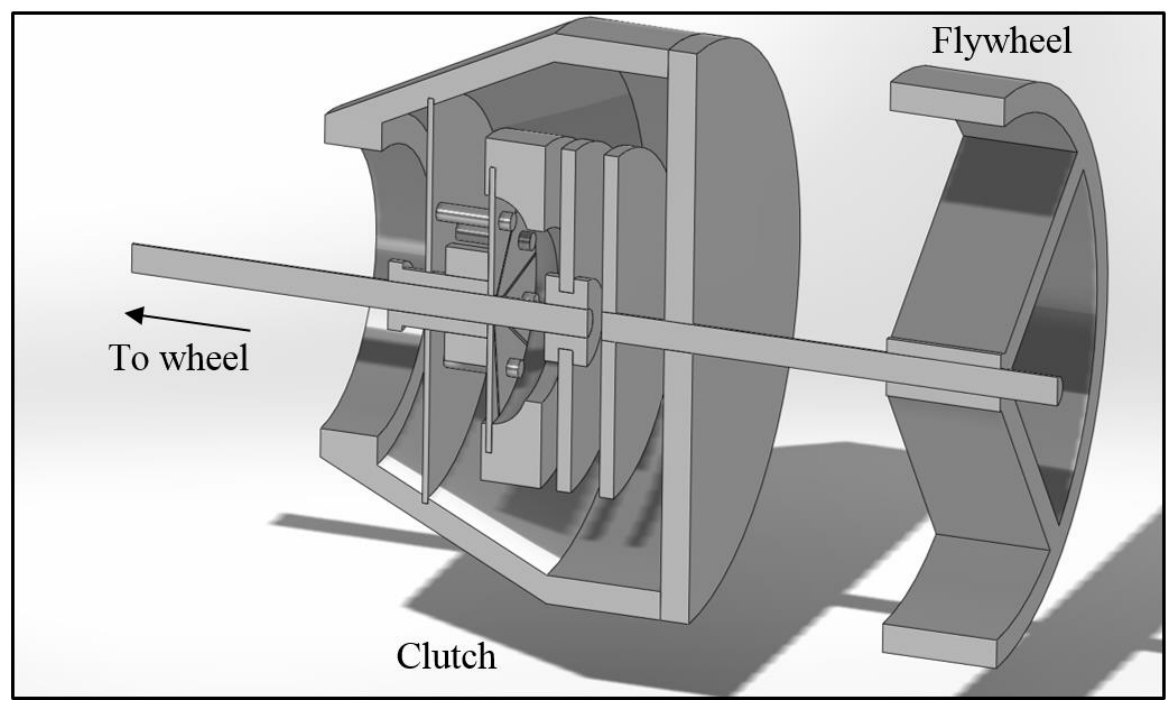

Fig. 2.2. Design of the flywheel RBS

\subsubsection{Flywheel-Pneumatic Regenerative Braking System}

As flywheels lose energy over time due to drag and friction between bearings, the addition of an accumulator to store a portion of the energy would help reduce the energy losses of the flywheel, as accumulators lose much less energy over time. Releasing this energy back to the flywheel provides higher energy that can be transferred back to the driveshaft for acceleration. This is the rationale behind the hybrid concept.

Figures 2.3 and 2.4 show the conceptual design of the flywheel-pneumatic hybrid RBS. The wheel mounted on the driveshaft will transfer the rotational energy to the flywheel 
through the activation of a conventional clutch system upon braking. A similar clutch is used in between the flywheel and pneumatic accumulator to transfer energy between the two systems. The accumulator is connected to the clutch by a shaft to the gear pump that draws air into the accumulator. A secondary gear is used to transfer the energy back to the flywheel in the same rotational direction

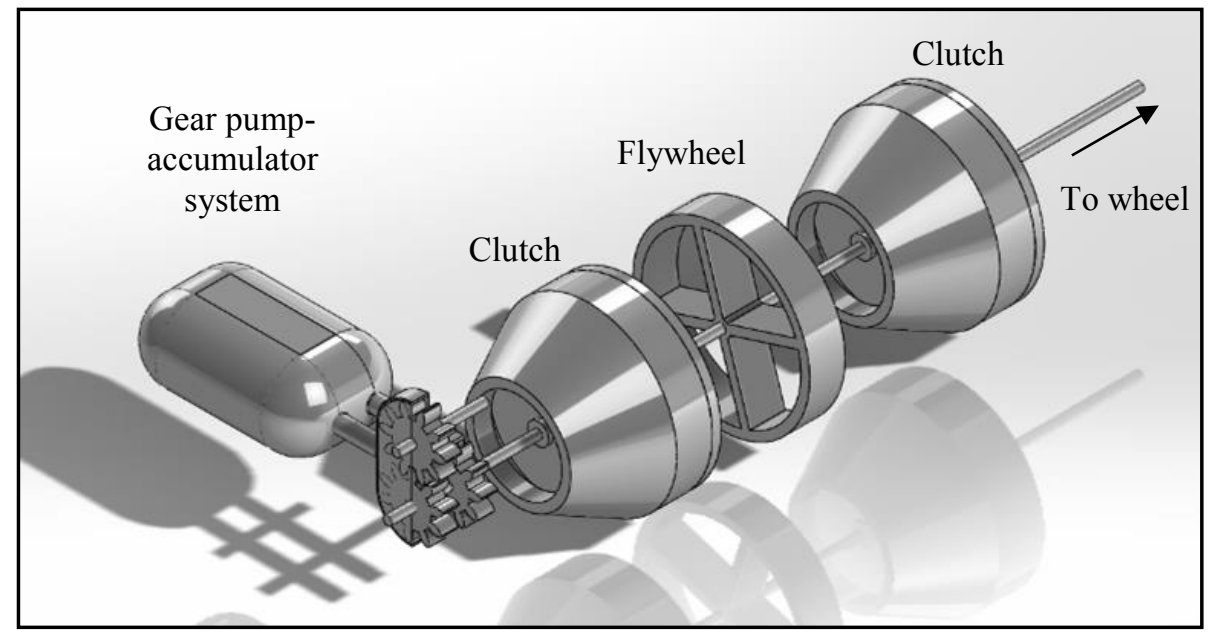

Fig. 2.3. Theoretical Design of the flywheel-pneumatic hybrid RBS

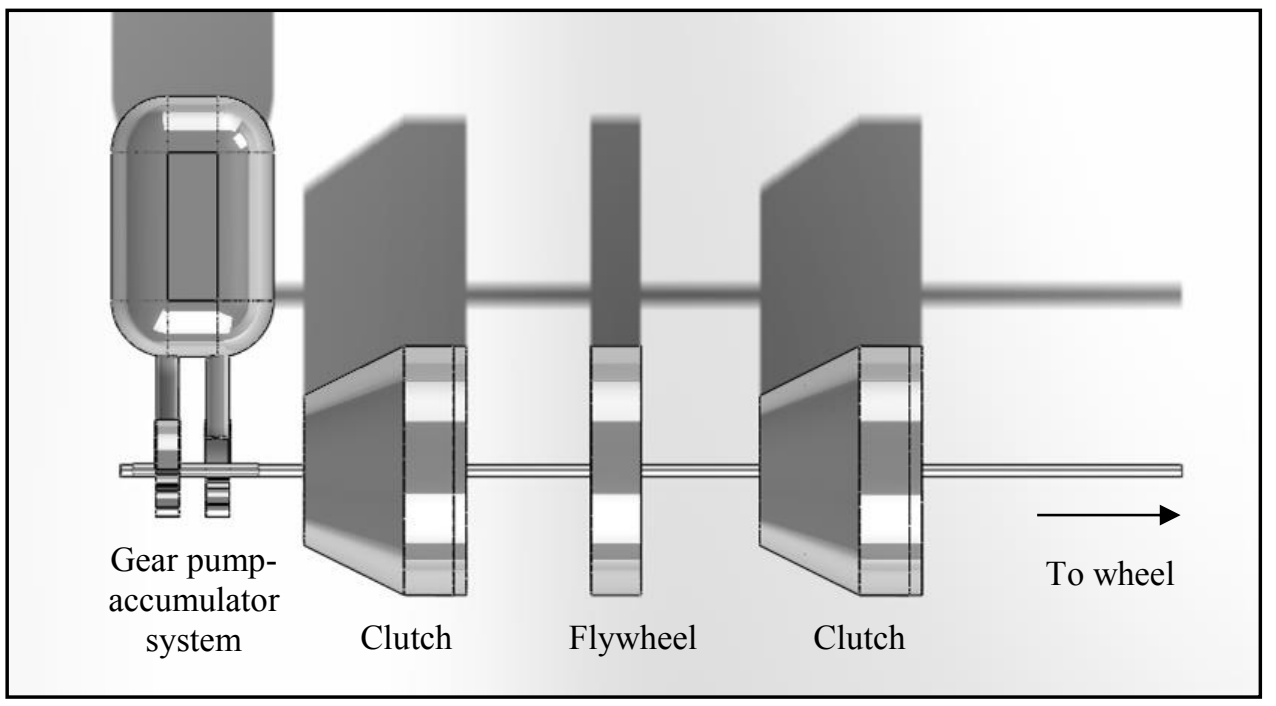

Fig. 2.4. Top view of the flywheel-pneumatic hybrid RBS

\subsection{Analysis}

The analysis was performed by running simulations of analytical models using Microsoft Excel version 2016. This computer software was used to process various parameters and energy equations for the flywheel RBS and the flywheel-pneumatic hybrid RBS.

\subsubsection{Parameters}


The flywheel was modeled with a set of variable parameters shown in Table 2.2. These variables determined the energy storage and losses of the ERS of the systems. The values of the variables shown in the table were applied to the analysis of the system and then varied to determine the effect of these parameters on the energy efficiency of the system. The flywheel was chosen to be a rim type with spokes to reduce chance of disintegration of material [7]. The angular velocity of the flywheel was chosen based on low speed applications below $3000 \mathrm{rpm}$ and high-speed applications between $3000 \mathrm{rpm}$ and 60000 rpm. The flywheel was chosen to be of S-glass epoxy material as it has more than double the energy density value of common cast iron flywheels [8]. The mass was varied around the average flywheel mass of around $65 \mathrm{~kg}$ [4]. This volume change was done by reducing thickness of the flywheel while the diameter values were kept constant. This was done by determining the volume of the cylinder based on the varying mass to thus alter the thickness value as shown in Eq. (1):

Volume of Flywheel, $V_{f}\left(\mathrm{~m}^{3}\right)$ :

$$
V_{f}=\pi t\left[\left(\frac{d_{o}}{2}\right)^{2}-\left(\frac{d_{i}}{2}\right)^{2}\right]
$$

Where

$t=$ Flywheel thickness (m)

$d_{o}=$ Outer diameter of the flywheel (m)

$d_{i}=$ Inner diameter of the flywheel $(\mathrm{m})$

Table 2.2. Initial variable flywheel parameters for analysis

\begin{tabular}{|c|c|}
\hline Flywheel parameter & Value \\
\hline Mass, $m(\mathrm{~kg})$ & 70.00 \\
\hline Outer diameter, $d_{o}(\mathrm{~m})$ & 0.50 \\
\hline Inner diameter, $d_{i}(\mathrm{~m})$ & 0.25 \\
\hline Thickness, $T_{f}(\mathrm{~m})$ & 0.05 \\
\hline
\end{tabular}

Table 2.3 shows constant parameters such as the density of air, dynamic viscousity of air, and gravitational acceleration.

Table 2.3. Parameters for simulations

\begin{tabular}{|c|c|}
\hline Constant & Value \\
\hline Density of air, $\rho_{\alpha}\left(\mathrm{kg} / \mathrm{m}^{3}\right)$ & 1.225 \\
\hline Dynamic viscousity of air, $\boldsymbol{b}_{\alpha}\left(\mathrm{Ns} / \mathrm{m}^{2}\right)$ & $1.983 \times 10^{-5}$ \\
\hline Gravitational acceleration, $g\left(\mathrm{~m} / \mathrm{s}^{2}\right)$ & 9.810 \\
\hline
\end{tabular}

Parameters for the flywheel ball bearing are shown in Table 2.4. The ball bearing is used to connect the flywheel to the shaft and is a deep groove ball bearing. They include the constant friction coefficient of ball bearings, radius of the shaft that connects to the ball bearings, and the corrective force factor for unbalanced and gyroscopic forces [9].

Table 2.4. Ball bearing parameters for simulations

\begin{tabular}{|c|c|}
\hline Ball bearing parameter & Value \\
\hline Friction coefficient, $\mu$ & $1.50 \times 10^{-3}$ \\
\hline
\end{tabular}




\begin{tabular}{|c|c|}
\hline Radius of shaft, $r_{s}(\mathrm{~m})$ & 0.05 \\
\hline Corrective force factor, $\boldsymbol{\gamma}$ & 1.00 \\
\hline
\end{tabular}

The clutch discs were modeled with parameters based on technical specifications of clutch disc manufacturers [10]. These values are shown in Table 2.5.

Table 2.5. Clutch discs parameters

\begin{tabular}{|c|c|}
\hline Clutch discs parameter & Value \\
\hline Clutch mass, $M_{C}(\mathrm{~kg})$ & 5.44311 \\
\hline Clutch diameter, $D_{C}(\mathrm{~m})$ & 0.18415 \\
\hline Clutch radius, $r_{C}(\mathrm{~m})$ & 0.09208 \\
\hline
\end{tabular}

\subsubsection{Energy equations}

The equations applied to simulate the two RBS included mass moment of inertia, energy storage, power losses, energy losses, and final energy efficiency equations. These equations are shown in Eq. (1) previously mentioned and Eqs. (2) to (13) as follows:

Mass moment of inertia of a flywheel, $I\left(\mathrm{~kg} . \mathrm{m}^{2}\right)$ [11]:

$$
I=\frac{1}{2} \cdot m \cdot\left(r_{o}^{2}+r_{i}^{2}\right)
$$

Where

$m=$ Mass of flywheel $(\mathrm{kg})$

$r_{o}=$ Outer radius of flywheel $(\mathrm{m})$

$r_{i}=$ Inner radius of flywheel $(\mathrm{m})$

Initial kinetic energy of a flywheel, $K E_{i}(J)[7]$ :

$$
K E_{i}=\frac{1}{2} \cdot I \cdot \omega^{2}
$$

Where

$\omega=$ Angular velocity of the flywheel $(\mathrm{rad} / \mathrm{s})$

Power loss due to air resistance of a flywheel, $P_{a, l}(W)[9]:$

$$
P_{a, l}=0.04 \cdot \rho_{a}^{0.8} \cdot \beta_{a}^{0.2} \cdot(\omega \cdot r)^{2.8} \cdot(2 . r)^{1.8} \cdot(\alpha+0.33)
$$

Where

$\rho_{\alpha}=$ Density of air $\left(\mathrm{kg} / \mathrm{m}^{3}\right)$

$\rho_{\alpha}=$ Dynamic viscosity of air $\left(\mathrm{Ns} / \mathrm{m}^{2}\right)$

$\omega=$ Angular velocity of the cylinder $(\mathrm{rad} / \mathrm{s})$

$r=$ Outer radius of the cylinder (m)

Geometric ratio, $\alpha=\frac{h}{2 . r}$ 
Where

$h=$ Thickness of the cylinder (m)

Power loss due to friction of bearings of a flywheel, $P_{b, l}(W)$ [9]:

$$
P_{b, l}=\mu \cdot \gamma \cdot r_{s} \cdot m \cdot g \cdot \omega_{b}
$$

Where

$\mu=$ Friction coefficient

$\gamma=$ Corrective force factor considering unbalanced and gyroscopic forces

$r_{s}=$ Radius of the shaft $(\mathrm{m})$

$\mathrm{m}=$ Mass of the flywheel $(\mathrm{kg})$

$g=$ Gravitational acceleration $\left(\mathrm{m} / \mathrm{s}^{2}\right)$

$\omega_{b}=$ Angular velocity of the bearing $(\mathrm{rad} / \mathrm{s})$

Total power loss of a flywheel, $P_{T}(\mathrm{~W})[9]$ :

$$
P_{T}=P_{\alpha, l}+P_{b, l}
$$

Total energy lost due to power losses, $E_{l}(\mathrm{~J})$ :

$$
E_{l}=P_{T} \times t
$$

Where

$t=$ Time of flywheel rotation (s)

Final energy of the flywheel system, $E_{f}(\mathrm{~J})$ :

$$
K E_{f}=K E_{i}-E_{l}
$$

Final angular velocity of the flywheel, $\omega_{f}(\mathrm{rad} / \mathrm{s})$ :

$$
\omega_{f}=\sqrt{\frac{2 \times K E_{f}}{I}}
$$

Final energy efficiency of the system, $\eta_{E}(\%)$ :

$$
\eta_{E}=\frac{K E_{f}}{K E_{i}} \times 100 \%
$$

Moment of inertia of clutch discs 1 and $2, I_{1}$ and $I_{2}\left(\mathrm{~kg} . \mathrm{m}^{2}\right)$ [12]: 


$$
I_{1}=I_{2}=\frac{1}{2} \times m_{C} \times r_{C}^{2}
$$

Where

$m_{C}=$ Mass of clutch disc $(\mathrm{kg})$

$r_{C}=$ Radius of clutch disc (m)

Energy loss due to clutch system, $P_{C}(W)[13]:$

$$
E_{C}=\frac{I_{1} I_{2} \times\left(\omega_{1}-\omega_{2}\right)^{2}}{2 I_{1} I_{2}}
$$

Where

$\omega_{1}=$ Angular velocity of clutch disc $1(\mathrm{rad} / \mathrm{s})$

$\omega_{1}=$ Angular velocity of clutch disc $2(\mathrm{rad} / \mathrm{s})$

Energy efficiency of gear pump-accumulator system, $\eta_{A}(\%)[14]$ :

$$
\eta_{S}=\eta_{G P} \times \eta_{A} \times \eta_{G P}
$$

Where

$\eta_{S}=$ Efficiency of gear pump-accumulator system (\%)

$\eta_{G P}=$ Efficiency of gear pump (\%)

$\eta_{A}=$ Efficiency of pneumatic accumulator (\%)

\subsubsection{Assumptions}

The analytical modeling was based on several assumptions as follow:

- Mass of the spokes of the flywheel were considered to be negligible

- The operation of the clutch system happens instantaneously

- Corrective force factor was assumed to be 1 based on assumption that gyroscopic forces do not highly affect the power losses due to bearing friction

- Dynamic viscousity of air based on assumption that air is at room temperature

\section{Results and Discussion}

\subsection{Validation of the Analytical Model}

The analytical model was validated with existing literature [15]. The parameters that were set are as shown in Table 3.1, while the results are shown in Figure 3.1:

Table 3.1. Parameters provided by literature source used in simulation [15].

\begin{tabular}{|c|c|}
\hline Parameter & Value \\
\hline Outer diameter of flywheel, $d_{o}(\mathrm{~m})$ & 0.330 \\
\hline Inner diameter of flywheel, $d_{i}(\mathrm{~m})$ & 0 \\
\hline
\end{tabular}




\begin{tabular}{|c|c|}
\hline Average radius of ball bearing, $r_{b}(\mathrm{~m})$ & 0.0385 \\
\hline Density of air, $\rho_{\alpha}\left(\mathrm{kg} / \mathrm{m}^{3}\right)$ & 1.225 \\
\hline Dynamic viscousity of air, $\beta_{\alpha}\left(\mathrm{Ns} / \mathrm{m}^{2}\right)$ & $1.983 \times 10^{-5}$ \\
\hline
\end{tabular}

The flywheel from literature was that of a solid flywheel without an inner diameter usually due to the ring flywheel design. The radius of the ball bearing was averaged and assumed as the radius of shaft, $r_{s}$ from Table 2.4.

Figure 3.1 shows that the power loss differences between the analytical model and literature was small, with the gradient difference of about only 7\%. Power losses itself by about 5 to $7 \mathrm{~W}$ between the model and literature.

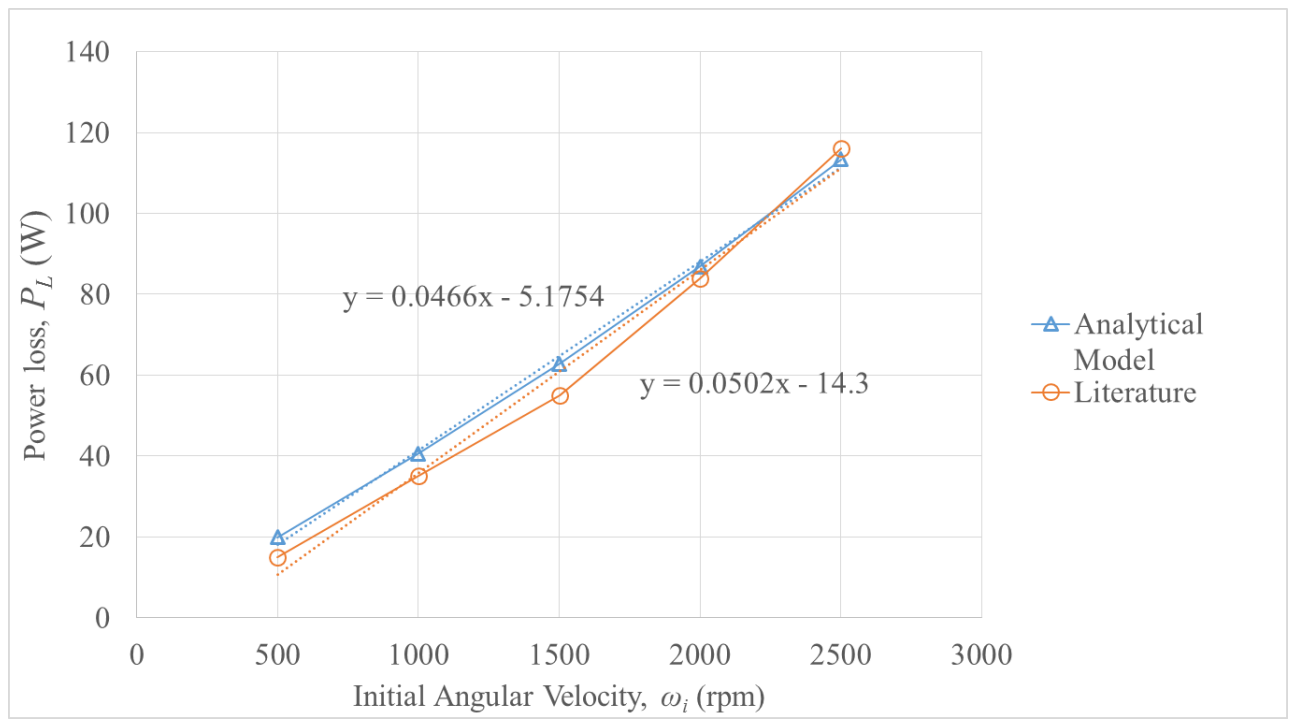

Fig. 3.1. Comparison of power loss between analytical model and literature.

Further comparisons with other literature sources mentioned that flywheels have about $70 \%$ to $90 \%$ efficiency for a short amount of time after the flywheel is left to rotate freely $[16,17]$. From the calculated efficiency of the modeled flywheel system using Eqs. (1) to (10), the results showed that at many varying parameters tested a $90 \%$ to $100 \%$ energy efficiency was available for the first few seconds of the simulation. The values then drop quickly to below $90 \%$, as in line with the information gained from the literature.

\subsection{Comparison of Energy Efficiencies of Simulated Systems}

\subsubsection{Effect of Mass of Flywheel on Energy Efficiency}

A heavier flywheel of $100 \mathrm{~kg}$ resulted the best performance in terms of energy efficiency values, while lower mass flywheels of $8.5 \mathrm{~kg}$ and $25 \mathrm{~kg}$ showed higher improvements in the hybrid RBS over the Flywheel RBS counterparts, as shown in Figure 3.2. Initial increase in energy efficiency occurs as the ratio of amount of energy recovered from braking relative to the losses due to the inefficiency of the gear system increases. Eventually, the power losses due to increasing angular velocity outweigh the energy stored in the accumulator and thus cause the efficiency to drop. 
The overall improvements due to mass begin to decrease at a faster rate than the heavier flywheels, causing a limitation to the required total time for positive energy efficiency gains. Heavier flywheels will also require power from the driveshaft to accelerate a vehicle carrying the heavier flywheel. This trade-off between weight and power needs to be carefully considered in view of overall fuel efficiency.

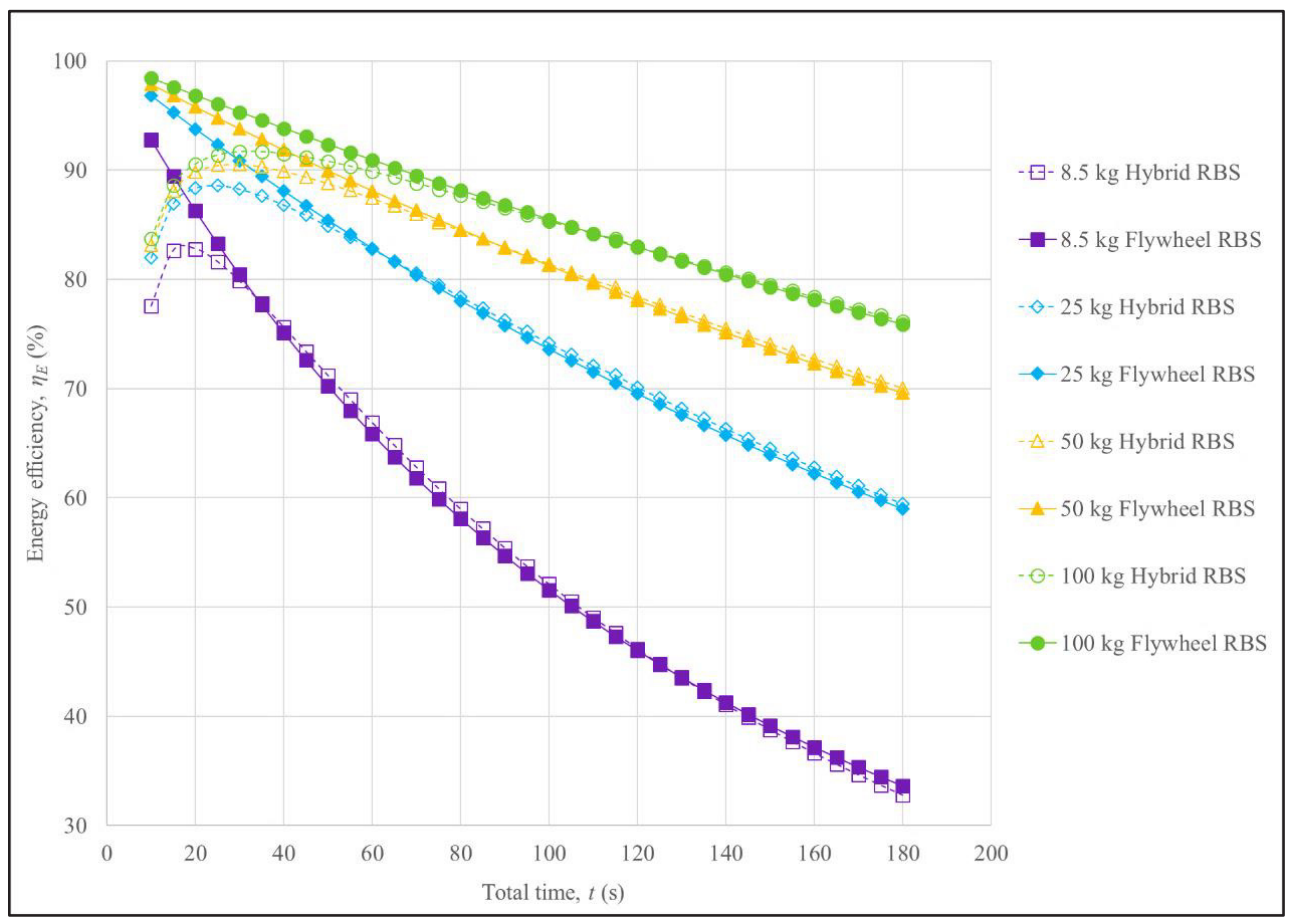

Fig 3.2. Effect of various flywheel masses on energy efficiency

\subsubsection{Effect of Initial Angular Velocity on Energy Efficiency}

Low angular velocity of $750 \mathrm{rpm}$ is the most energy efficient but also has the lowest maximum energy storage available as shown in Figure 3.3. Thus, a low angular velocity may not be able to power a vehicle for acceleration as compared with a faster flywheel system that is less energy efficient but has more energy available to be used by the driver of the vehicle. 


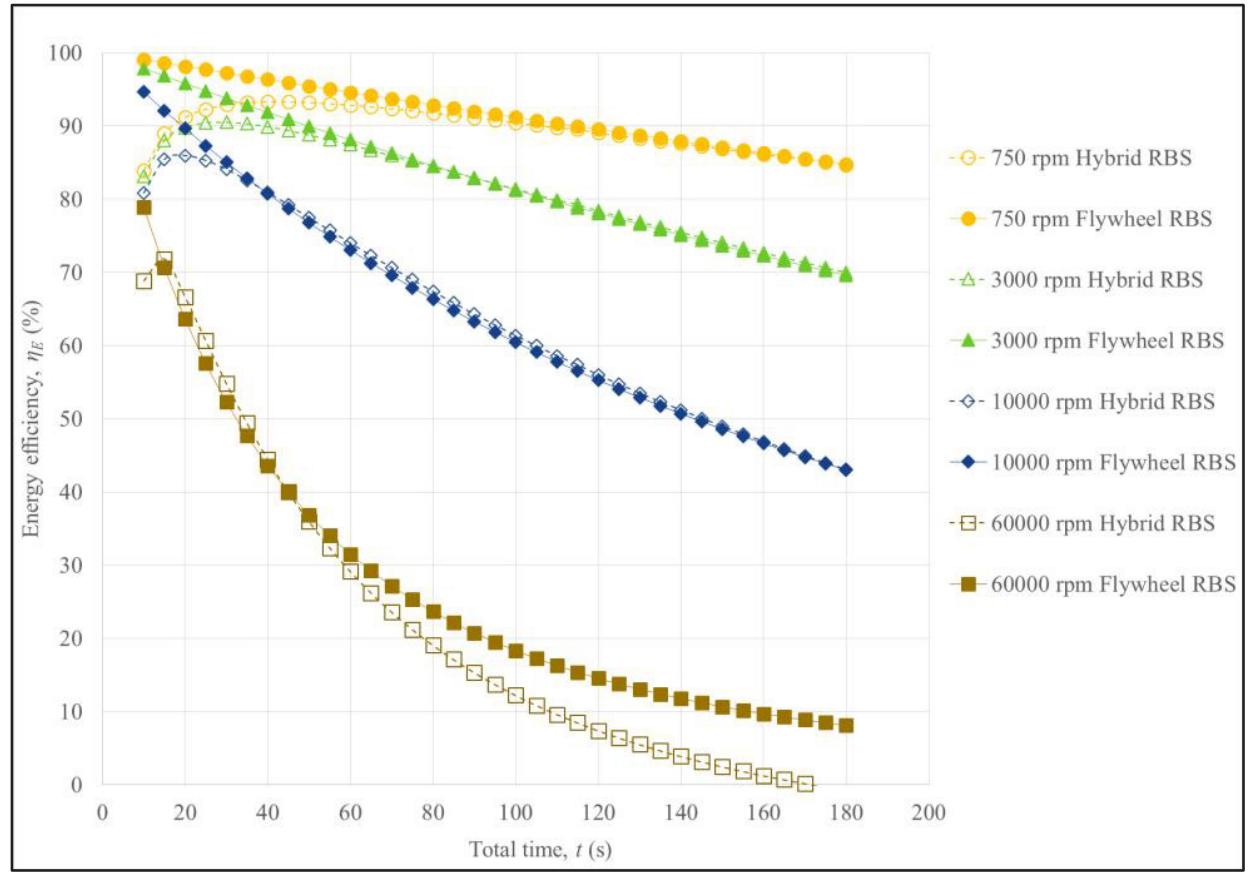

Fig. 3.3. Effect of various initial angular velocities on energy efficiency

\subsubsection{Effect of Energy Transfer and Storage Time on Energy Efficiency}

Low transfer times resulted in the highest energy efficiency as shown in Figure 3.4. However, the inconsistency of vehicle idle time during daily driving may not always call for total energy storage times of 180 seconds or less. As the energy efficiency of shorter transfer times close up on the energy efficiency provided by larger transfer times, an expected breakeven point and negative difference may cause the longer transfer times to be

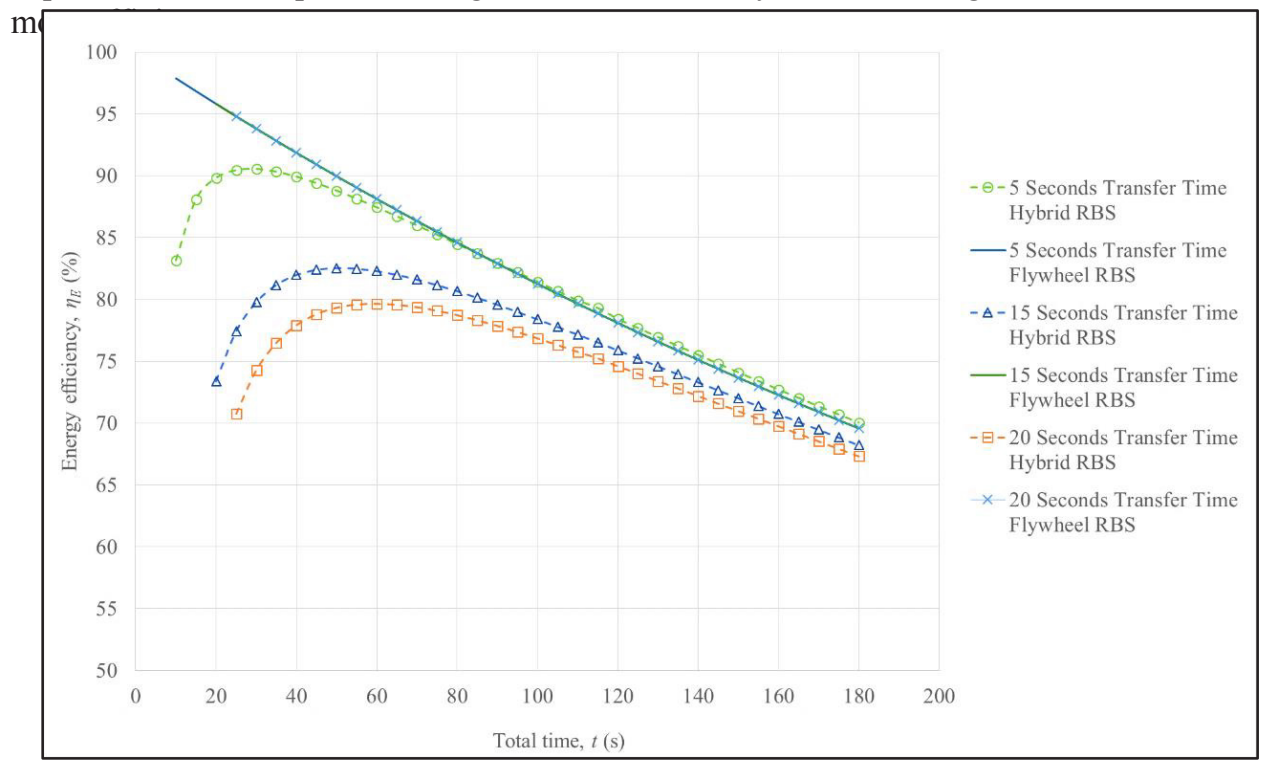


Fig. 3.4. Effect of various transfer and storage times on energy efficiency

3.2 Comparison with Existing Flybrid Flywheel System

Figure 3.5 shows the highest energy efficiency values for the flywheel and HRBS compared with the current Flybrid Flywheel system. The hybrid system was able to improve on the Flybrid Flywheel system, but was not able to surpass the flywheel system in terms of energy efficiency. This comparison between the modeled and current systems is however not a direct comparison due to the very different parameters and also that the Flybrid Flywheel efficiency was not given as a function of time in the literature. Specifically, the increase in mass of the flywheel will cause an increase in power needed by the vehicle to accelerate, while the lower mass Flybrid Flywheel system does not add as much to the total vehicle mass.

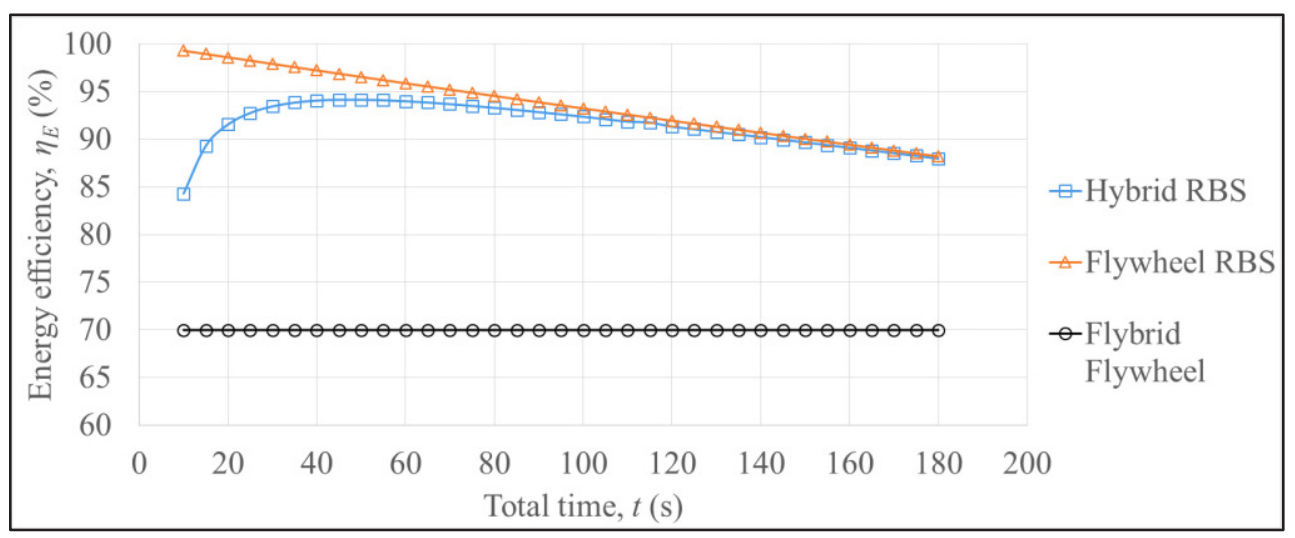

Fig. 3.5. Comparison of simulated systems with existing Flybrid Flywheel system

\section{Conclusions and Future Work}

The energy losses can be seen as factors that greatly affect the energy efficiencies of the regenerative braking systems. This is due to the high angular velocities that cause very high power losses to air resistance and bearing friction. This analysis has shown that the flywheel-pneumatic hybrid system is at times able to provide an improvement in energy efficiency to current systems within a range of suitable parameters only such as a high mass value of $50 \mathrm{~kg}$ to $100 \mathrm{~kg}$, low angular velocity of $750 \mathrm{rpm}$ to $3000 \mathrm{rpm}$, and low or short energy transfer times of 5 seconds or less between the flywheel and the pneumatic accumulator.

However, overall energy values that are available for usage are not enough to take advantage of the energy efficiency due to the low angular velocity, which the Flybrid Flywheel system avoids by mitigating the losses. Furthermore, as the mass of the flywheel increases, power required to accelerate the vehicle increases. Research could be done to determine if the energy efficiency provided by the increase in mass is able to overcome the additional energy required to power the heavier vehicle.

It is hoped that these findings can contribute to further the field of knowledge of hybrid mechanical RBS regarding energy storage and efficiency. Future work could focus on reducing energy losses and producing working prototypes for experimental analysis. 


\section{References}

1. P. Gupta, A. Kumar, and S. Deb, International Journal of Mechanical And Production Engineering, 2, 75-78 (2014)

2. R. Ramakrishnan, S. S. Hiremath, and M. Singaperumal, J. Mech. Sci. Technol., 26, 1321-1331 (2012)

3. U. Diego-Ayala, et al., Proc. Inst. Mech. Eng. Part D J. Automob. Eng., 222, 2087$2101(2008)$

4. Gabriel-Buenaventura, Alejandro, and B. Azzopardi, Renew. Sustain. Energy Rev., 41, 955-964 (2015)

5. J. B. M. William, C. David, J Automobile Engineering, 1, 1-14 (2012)

6. S. J. Clegg, Institute of Transport Studies, University of Leeds, 471 (1996)

7. H. Liu and J. Jiang, Energy Build, 39, 599-604 (2007)

8. A. Shinde, et al., Global Journal of Enterprise Information System, 9, 95-99 (2017)

9. X. Zhang, C. Mi, Vehicle Power Management, 86-89 (2011)

10. Tilton Engineering. "Ford Clutch-Flywheel Assemblies". Internet: http://tiltonracing.com/product/ford-clutch-flywheel-assemblies/ (2017)

11. B. Bolund, et al., Renewable and Sustainable Energy Reviews, 11, 235-258 (2007)

12. C. R. Nave. "Thick hoop and hollow cylinders". Internet: http://hyperphysics.phyastr.gsu.edu/hbase/ihoop.html (2016)

13. B. I. Silviu, et al., Recent Researches in Automatic Control, May, 252-256 (2011)

14. R. J. V. Mark, J. W. Steven, J. R. Donald, J. M. Timothy, US Patent 8,622,860 (2014)

15. J. Abrahamsson, et al., energies, 5, 2794-2817 (2012)

16. I. Hadjipaschalis, et al., Renewable and Sustainable Energy Reviews, 13, 1513-1522 (2009)

17. A. Boretti, International Journal of Hydrogen Energy, 35, 8417-8424 (2010) 